\title{
EXPLICIT SOLUTIONS OF THE CONFLUENT HYPERGEOMETRIC EQUATIN BY MEANS OF THE DIFFERINTEGRAL THEOREMS
}

\author{
(DIFERINTEGRAL TEOREMLERI YARDIMIYLA KONFLUENT \\ HIPERGEOMETRIK DENKLEMININ AÇIK ÇÖZÜMLERI)
}

\section{Ökkeş ÖZTÜRK ${ }^{1}$}

\begin{abstract}
In fractional calculus, an area of applied mathematics, the differintegral is a combined differentiation/integration operator. Differintegral theory is used to solve some classes of differential equations and fractional differential equations. One of these equations is the confluent hypergeometric equation. In this paper, we intend to solve this equation by means of the differintegral theorems.
\end{abstract}

Keywords: Fractional calculus, Differintegral, Confluent hypergeometric equation, Differintegral theorems, Generalized Leibniz rule

\section{$\ddot{O} Z$}

Uygulamalı matematiğin bir alanı olan kesirli hesapta diferintegral, türev/integral operatörünün bir birleşimidir. Diferansiyel denklemlerin ve kesirli diferansiyel denklemlerin bazı sınıflarını çözmek için diferintegral teorisi kullanılmaktadır. Bu denklemlerden birisi konfluent hipergeometrik denklemidir. Bu makalede, diferintegral teoremleri yardımıyla bu denklemi çözmeyi hedefleriz.

Anahtar Kelimeler: Kesirli hesap, Diferintegral, Konfluent hipergeometrik denklemi, Diferintegral teoremleri, Genelleştirilmiş Leibniz kuralı

\footnotetext{
${ }^{1}$ Bitlis Eren Üniversitesi, Fen-Edebiyat Fakültesi, Matematik Bölümü, BİTLİS, oozturk@beu.edu.tr (Sorumlu Yazar)
} 


\section{INTRODUCTION}

The widely investigated subject of fractional calculus (that is, calculus of derivatives and integrals of any arbitrary real or complex order) has gained considerable importance and popularity during the past three decades or so, due chiefly to its demonstrated applications in numerous seemingly diverse fields of science and engineering. We can mention that the fractional differential equations are playing an important role in fluid dynamics, traffic model with fractional derivative, measurement of viscoelastic material properties, modeling of viscoplasticity, control theory, relativity theory, economy, nuclear magnetic resonance, geometric mechanics, mechanics, optics, signal processing, robot technology, PID control systems, Schrödinger equation, heat transfer, filtration and so on.

Some of most obvious formulations based on the fundamental definitions of RiemannLiouville fractional differentiation and fractional integration are, respectively,

$$
{ }_{a} D_{t}^{\mu} f(t)=\frac{1}{\Gamma(k-\mu)} \frac{d^{k}}{d t^{k}} \int_{a}^{t} f(\tau)(t-\tau)^{k-\mu-1} d \tau \quad(k-1 \leq \mu<k),
$$

and,

$$
{ }_{a} D_{t}^{-\mu} f(t)=\frac{1}{\Gamma(\mu)} \int_{a}^{t} f(\tau)(t-\tau)^{\mu-1} d \tau \quad(t>a, \mu>0)
$$

where $k \in \mathbb{N}, \mathbb{N}$ being the set of positive integers, $\Gamma$ stands for Euler's function gamma [1-4].

Recently, by applying the Riemann-Liouville definitions of a differintegral (that is, fractional derivative and fractional integral) of order $\mu \in \mathbb{R}$, many authors have explicity obtained particular solutions of a number of families of homogeneous (as well as nonhomogeneous) linear ordinary and partial differintegral equations (see, for details, [5]; see also [6,7]). An important example of Fuchsian differential equations is provided by the celebrated hypergeometric equation (or, more precisely, the Gauss hypergeometric equation)

$$
z(1-z) \frac{d^{2} u}{d z^{2}}+[\gamma-(\alpha+\beta+1) z] \frac{d u}{d z}-\alpha \beta u=0
$$

whose study can be traced back to L. Euler, C.F. Gauss and E.E. Kummer. On the other hand, a special limit (confluent) case of the Gauss hypergeometric equation, in the form [8]

$$
\frac{d^{2} u}{d z^{2}}+\left(-\frac{1}{4}+\frac{\varkappa}{z}-\frac{\ell(\ell+1)}{z^{2}}\right) u=0 \quad\left(\mu=\ell+\frac{1}{2}\right)
$$

is refered to as the Whittaker equation whose systematic study was initiated by E.T. Whittaker.

Other classes of non-Fuchsian differential equations which we shall consider in this investigation include the so-called Fukuhara equation [9] 


$$
z^{2} \frac{d^{2} u}{d z^{2}}+z \frac{d u}{d z}-\left(1-z+z^{2}\right) u=0
$$

the Tricomi equation [10]

$$
\frac{d^{2} u}{d z^{2}}+\left(\alpha+\frac{\beta}{z}\right) \frac{d u}{d z}+\left(\gamma+\frac{\delta}{z}+\frac{\varepsilon}{z^{2}}\right) u=0
$$

and the Bessel equation [11]

$$
z^{2} \frac{d^{2} u}{d z^{2}}+z \frac{d u}{d z}-\left(z^{2}-v^{2}\right) u=0
$$

Moreover, in [12], Inc obtained the particular solutions of the confluent hypergeometric differential equation by using the nabla fractional calculus operator which is an important operator in discrete fractional calculus. Virchenko's study [13] is devoted to further development of important case of Wright's hypergeometric function and its applications to the generalization of $\Gamma-, B-, \psi-, \zeta-$, Volterra functions. In [14], Srivastava and Saxena expressed some Volterra-type fractional integro-differential equations with a multivariable confluent hypergeometric function as their kernel. And, Campos solved the extended confluent hypergeometric differential equation in [15].

In this paper, we also obtained the fractional solutions of the confluent hypergeometric equation by using the differintegral theorems. The most important advantage of these theorems is applicaple to the singular equations.

\section{MATERIALS AND METHODS}

2.1. Definition If the function $f(z)$ is analytic (regular) inside and on $C$, where $C=$ $\left\{C^{-}, C^{+}\right\}, C^{-}$is a contour along the cut joining the points $z$ and $-\infty+i \operatorname{Im}(z)$, which starts from the point at $-\infty$, encircles the point $z$ once counter-clockwise, and returns to the point at $-\infty$, and $C^{+}$is a contour along the cut joining the points $z$ and $\infty+i \operatorname{Im}(z)$, which starts from the point at $\infty$, encircles the point $z$ once counter-clockwise, and returns to the point at $\infty$,

$$
\begin{aligned}
& f_{\mu}(z)=[f(z)]_{\mu}=\frac{\Gamma(\mu+1)}{2 \pi i} \int_{C} \frac{f(\tau) d \tau}{(\tau-z)^{\mu+1}} \quad\left(\mu \notin \mathbb{Z}^{-}\right), \\
& f_{-k}(z)=\lim _{\mu \rightarrow-k} f_{\mu}(z) \quad\left(k \in \mathbb{Z}^{+}\right),
\end{aligned}
$$

where $\tau \neq z$,

$$
\begin{aligned}
& -\pi \leq \arg (\tau-z) \leq \pi \text { for } C^{-} \text {, } \\
& 0 \leq \arg (\tau-z) \leq 2 \pi \text { for } C^{+} \text {. }
\end{aligned}
$$

In that case, $f_{\mu}(z)(\mu>0)$ is the fractional derivative of $f(z)$ of order $\mu$ and $f_{\mu}(z)(\mu<$ 0 ) is the fractional integral of $f(z)$ of order $-\mu$, confirmed (in each case) that

$$
\left|f_{\mu}(z)\right|<\infty \quad(\mu \in \mathbb{R})
$$


[4].

2.2. Lemma (Linearity) Let $f(z)$ and $g(z)$ be analytic and single-valued functions. If $f_{\mu}$ and $g_{\mu}$ exist, then

(i) $\left[c_{1} f(z)\right]_{\mu}=c_{1}[f(z)]_{\mu}$,

(ii) $\left[c_{1} f(z)+c_{2} g(z)\right]_{\mu}=c_{1}[f(z)]_{\mu}+c_{2}[g(z)]_{\mu}$,

where $c_{1}$ and $c_{2}$ are constants and $\mu \in \mathbb{R}, z \in \mathbb{C}$.

2.3. Lemma (Index law) Let $f(z)$ be an analytic and single-valued function. If $\left(f_{v}\right)_{\mu}$ and $\left(f_{\mu}\right)_{v}$ exist, then

$$
\left\{[f(z)]_{v}\right\}_{\mu}=[f(z)]_{v+\mu}=\left\{[f(z)]_{\mu}\right\}_{v^{\prime}}
$$

where $v, \mu \in \mathbb{R}, z \in \mathbb{C}$ and $\left|\frac{\Gamma(v+\mu+1)}{\Gamma(v+1) \Gamma(\mu+1)}\right|<\infty$.

2.4. Lemma (Generalized Leibniz rule) Let $f(z)$ and $g(z)$ be single-valued and analytic functions. If $f_{\mu}$ and $g_{\mu}$ exist, then

$$
(f . g)_{\mu}=\sum_{k=0}^{\infty} \frac{\Gamma(\mu+1)}{\Gamma(\mu+1-k) \Gamma(k+1)} f_{\mu-k} \cdot g_{k}
$$

where $\mu \in \mathbb{R}, z \in \mathbb{C}$ and $\left|\frac{\Gamma(\mu+1)}{\Gamma(\mu+1-k) \Gamma(k+1)}\right|<\infty$.

2.5. Property For a constant $\lambda$,

$$
\left(\mathrm{e}^{\lambda \mathrm{z}}\right)_{v}=\lambda^{v} \mathrm{e}^{\lambda z} \quad(\lambda \neq 0, v \in \mathbb{R}, \mathrm{z} \in \mathbb{C})
$$

2.6. Property For a constant $\lambda$,

$$
\left(\mathrm{e}^{-\lambda z}\right)_{v}=\mathrm{e}^{-i \pi v} \lambda^{v} \mathrm{e}^{-\lambda z} \quad(\lambda \neq 0, v \in \mathbb{R}, z \in \mathbb{C}) .
$$

2.7. Property For a constant $\lambda$,

$$
\left(z^{\lambda}\right)_{v}=\mathrm{e}^{-i \pi v} z^{\lambda-v} \frac{\Gamma(v-\lambda)}{\Gamma(-\lambda)} \quad\left(v \in \mathbb{R}, z \in \mathbb{C},\left|\frac{\Gamma(v-\lambda)}{\Gamma(-\lambda)}\right|<\infty\right) .
$$

\subsection{Property}

$$
\Gamma(z+1)=z \Gamma(z+1)=z !
$$

and, 


$$
\Gamma(v-k)=(-1)^{k} \frac{\Gamma(v) \Gamma(1-v)}{\Gamma(k+1-v)}
$$

where $k \in \mathbb{Z}_{0}^{+}$and $v \in \mathbb{R}$.

2.9. Theorem Let $\mathcal{P}(z ; p)$ and $\mathcal{Q}(z ; q)$ be polynomials in $z$ of degrees $p$ and $q$, respectively, defined by

$$
\mathcal{P}(z ; p)=\sum_{k=0}^{p} a_{k} z^{p-k}=a_{0} \prod_{j=1}^{p}\left(z-z_{j}\right) \quad\left(a_{0} \neq 0, p \in \mathbb{N}\right),
$$

and,

$$
\mathcal{Q}(z ; q)=\sum_{k=0}^{q} b_{k} z^{q-k} \quad\left(b_{0} \neq 0, q \in \mathbb{N}\right)
$$

Suppose also that $f_{-\mu} \neq 0$ exists for a given function $f$.

Then the nonhomogeneous linear ordinary fractional differintegral equation

$$
\begin{array}{r}
\mathcal{P}(z ; p) \varphi_{v}(z)+\left[\sum_{k=1}^{p}\left(\begin{array}{l}
\mu \\
k
\end{array}\right) \mathcal{P}_{k}(z ; p)+\sum_{k=1}^{q}\left(\begin{array}{c}
\mu \\
k-1
\end{array}\right) \mathcal{Q}_{k-1}(z ; q)\right] \varphi_{v-k}(z) \\
+\left(\begin{array}{l}
\mu \\
q
\end{array}\right) q ! b_{0} \varphi_{v-q-1}(z)=f(z) \quad(p, q \in \mathbb{N}, v, \mu \in \mathbb{R}),
\end{array}
$$

has a particular solution of the form

$$
\varphi(z)=\left\{\left[\frac{f_{-\mu}(z)}{\mathcal{P}(z ; p)} \mathrm{e}^{\mathcal{H}(z ; p, q)}\right]_{-1} \mathrm{e}^{-\mathcal{H}(z ; p, q)}\right\}_{\mu-v+1} \quad\left(z \in \mathbb{C} \backslash\left\{z_{1}, \ldots, z_{p}\right\}\right),
$$

where for suitable condition,

$$
\mathcal{H}(z ; p, q)=\int^{z} \frac{\mathcal{Q}(\xi ; q)}{\mathcal{P}(\xi ; p)} d \xi \quad\left(z \in \mathbb{C} \backslash\left\{z_{1}, \ldots, z_{p}\right\}\right)
$$

confirmed that the second component of (17) exists. Moreover, the homogeneous linear ordinary fractional differintegral equation

$$
\mathcal{P}(z ; p) \varphi_{v}(z)+\left[\sum_{k=1}^{p}\left(\begin{array}{l}
\mu \\
k
\end{array}\right) \mathcal{P}_{k}(z ; p)+\sum_{k=1}^{q}\left(\begin{array}{c}
\mu \\
k-1
\end{array}\right) \mathcal{Q}_{k-1}(z ; q)\right] \varphi_{v-k}(z)
$$




$$
+\left(\begin{array}{l}
\mu \\
q
\end{array}\right) q ! b_{0} \varphi_{v-q-1}(z)=0 \quad(p, q \in \mathbb{N}, v, \mu \in \mathbb{R})
$$

has solutions of the form

$$
\varphi(z)=K\left[\mathrm{e}^{-\mathcal{H}(z ; p, q)}\right]_{\mu-v+1}
$$

where $\mathcal{H}(z ; p, q)$ is given by (18), it being confirmed that the second component of (20) exist and $K$ is an arbitrary constant [16].

\section{MAIN RESULTS}

The hypergeometric equation

$$
x(1-x) \frac{d^{2} \varphi(x)}{d x^{2}}+[c-(a+b+1) x] \frac{d \varphi(x)}{d x}-a b \varphi(x)=0,
$$

has three regular singular points at $x=0,1$ and $\infty(a, b$ and $c$ are parameters $)$. By setting $x=$ $z / b$ and taking the limit as $b \rightarrow \infty$, we can merge the singularities at $b$ and infinity. This gives us the confluent equation as

$$
z \frac{d^{2} \varphi}{d z^{2}}+(c-z) \frac{d \varphi}{d z}-a \varphi=0
$$

solutions of which are the confluent hypergeometric functions, which are shown as $M(a, c ; z)$.

The confluent hypergeometric equation has a regular singular point at $z=0$ and an essential singularity at infinity. Bessel functions, $J_{n}(z)$, and the Laguerre polynomials, $L_{n}(z)$, can be written in terms of the solutions of the confluent hypergeometric equation as

$$
\begin{aligned}
& J_{n}(z)=\frac{\mathrm{e}^{-i z}}{n !}\left(\frac{z}{2}\right)^{n} M\left(n+\frac{1}{2}, 2 n+1 ; 2 i z\right), \\
& L_{n}(z)=M(-n, 1 ; z) .
\end{aligned}
$$

Linearly independent solutions of Eq. (22) are given as

$$
\begin{aligned}
& \varphi_{1}(z)=M(a, c ; z)=1+\frac{a}{c} \frac{z}{1 !}+\frac{a(a+1)}{c(c+1)} \frac{z^{2}}{2 !}+\frac{a(a+1)(a+2)}{c(c+1)(c+2)} \frac{z^{3}}{3 !}+\cdots, \\
& (c \neq 0,-1,-2, \ldots),
\end{aligned}
$$

and,

$$
\varphi_{2}(z)=z^{1-c} M(a+1-c, 2-c ; z) \quad(c \neq 2,3,4, \ldots) .
$$

Integral representation of the confluent hypergeometric functions, which are also shown as ${ }_{1} F_{1}(a, b ; z)$, can be given as 


$$
M(a, c ; z)=\frac{\Gamma(c)}{\Gamma(a) \Gamma(c-a)} \int_{0}^{1} \mathrm{e}^{z t} t^{a-1}(1-t)^{c-a-1} d t \quad(a, c \in \mathbb{R}, c>a>0) .
$$

Now, for Eq. (22), we use the transformation as

$$
\varphi(z)=z^{-c / 2} \mathrm{e}^{z / 2} u(z) \quad\left[u(z)=z^{c / 2} \mathrm{e}^{-z / 2} \varphi(z)\right] .
$$

So, we can write

$$
\frac{d \varphi}{d z}=z^{-\frac{c}{2}-1} \mathrm{e}^{z / 2}\left[z \frac{d u}{d z}+\frac{1}{2}(z-c) u\right]
$$

and,

$$
\frac{d^{2} \varphi}{d z^{2}}=z^{-\frac{c}{2}-2} \mathrm{e}^{z / 2}\left\{z^{2} \frac{d^{2} u}{d z^{2}}+z(z-c) \frac{d u}{d z}+\frac{1}{4}\left[(z-c)^{2}+2 c\right] u\right\}
$$

By substituting (23), (24) and (25) into (22), we have

$$
\frac{d^{2} u}{d z^{2}}+\left(-\frac{1}{4}+\frac{\frac{c}{2}-a}{z}+\frac{2 c-c^{2}}{4 z^{2}}\right) u=0
$$

After, we can write Eq. (26) as follows

$$
\frac{d^{2} u}{d z^{2}}+\left[-\frac{1}{4}+\frac{\frac{c}{2}-a}{z}+\frac{\frac{1}{4}-\left(\frac{c-1}{2}\right)^{2}}{z^{2}}\right] u=0
$$

By using Theorem (2.9), we have [18]

$$
\mu=2, \quad p=q=1, \quad a_{0}=h \neq 0, \quad a_{1}=0, \quad b_{0}=s \neq 0, \quad b_{1}=t,
$$

so that

$$
\mathcal{P}(z ; 1)=h z, \quad \mathcal{P}_{1}(z ; 1)=h,
$$

and,

$$
\mathcal{Q}(z ; 1)=s z+t, \quad \mathcal{Q}_{1}(z ; 1)=s .
$$

After, by using Eq. (18), we obtain 


$$
\mathcal{H}(z ; 1,1)=\int^{z} \frac{\mathcal{Q}(\xi ; 1)}{\mathcal{P}(\xi ; 1)} d \xi=\ln \left[(h z)^{t / h} \mathrm{e}^{s z / h}\right]
$$

3.1. Theorem Let $\left|f_{\mu}(z)\right|<\infty$ and $f_{-\mu} \neq 0$. The nonhomogeneous second order linear ordinary differential equation as

$$
h z \frac{d^{2} \varphi}{d z^{2}}+(s z+\mu h+t) \frac{d \varphi}{d z}+\mu s \varphi(z)=f(z) \quad(h \neq 0, \mu \in \mathbb{R}),
$$

has a solution as follows

$$
\varphi(z)=\left\{\left[f_{-\mu}(z)(h z)^{(t-h) / h} \mathrm{e}^{s z / h}\right]_{-1}(h z)^{-t / h} \mathrm{e}^{-s z / h}\right\}_{\mu-1}
$$

Furthermore, the homogeneous second order linear ordinary differential equation as

$$
h z \frac{d^{2} \varphi}{d z^{2}}+(s z+\mu h+t) \frac{d \varphi}{d z}+\mu s \varphi(z)=0 \quad(h \neq 0, \mu \in \mathbb{R})
$$

has a solution as follows

$$
\varphi(z)=K\left[(h z)^{-t / h} \mathrm{e}^{-s z / h}\right]_{\mu-1}
$$

where $K$ is an arbitrary constant [18].

Now, by using Theorem (3.1), we set

$h=1, \quad s=-1, \quad t=c-a, \quad \mu=a$.

So, we obtain the equation as

$z \frac{d^{2} \varphi}{d z^{2}}+(c-z) \frac{d \varphi}{d z}-a \varphi(z)=0$

After, we find the solution of Eq. (37) as follows

$\varphi(z)=K\left[z^{a-c} \mathrm{e}^{z}\right]_{a-1}$

Finally, we have the solution of Eq. (27) as

$$
u(z)=K z^{c / 2} \mathrm{e}^{-z / 2}\left[z^{a-c} \mathrm{e}^{z}\right]_{a-1} .
$$

3.2. Example Let $a=3$ and $c=1$ for Eq. (38) and Eq. (39). So, we obtain

$$
\varphi(z)=K\left(z^{2} \mathrm{e}^{z}\right)_{2},
$$

and, 
$u(z)=K z^{1 / 2} \mathrm{e}^{-z / 2}\left(z^{2} \mathrm{e}^{z}\right)_{2}$

By using Eq. (1), we have

$\left(z^{2} \mathrm{e}^{z}\right)_{2}=\frac{1}{\Gamma(1)} \frac{d^{3}}{d z^{3}} \int_{0}^{z} \tau^{2} \mathrm{e}^{\tau} d \tau=\mathrm{e}^{z}\left(z^{2}+4 z+2\right)$.

After, by substituting (42) into (40) and (41), we find the solutions as

$\varphi(z)=K \mathrm{e}^{z}\left(z^{2}+4 z+2\right)$,

and,

$$
u(z)=K z^{1 / 2} \mathrm{e}^{z / 2}\left(z^{2}+4 z+2\right) .
$$

3.3. Theorem Let $\left|\left(z^{a-c}\right)_{k}\right|<\infty\left(k \in \mathbb{Z}^{+} \cup\{0\}\right), z \neq 0$, and $\left|\frac{1}{z}\right|<1$. The solution of (38) can be written as follows

$$
\varphi(z)=K z^{a-c} \mathrm{e}^{z}{ }_{2} F_{0}\left[1-a, c-a ; \frac{1}{z}\right],
$$

where ${ }_{2} F_{0}$ is the Gauss hypergeometric function.

Proof. By means of (8), we have

$$
\varphi(z)=K \sum_{k=0}^{\infty} \frac{\Gamma(a)}{\Gamma(a-k) \Gamma(k+1)}\left(z^{a-c}\right)_{k}\left(\mathrm{e}^{z}\right)_{a-1-k} .
$$

By using (9), (11), (12) and (13), we can rewrite the Eq. (46) as follows

$$
\begin{aligned}
\varphi(z) & =K \sum_{k=0}^{\infty} \frac{\Gamma(k+1-a)}{(-1)^{k} \Gamma(1-a)} \frac{1}{k !}(-1)^{k} z^{a-c-k} \frac{\Gamma(k+c-a)}{\Gamma(c-a)} \mathrm{e}^{z}, \\
& =K z^{a-c} \mathrm{e}^{z} \sum_{k=0}^{\infty}[1-a]_{k}[c-a]_{k} \frac{1}{k !}\left(\frac{1}{z}\right)^{k}, \\
& =K z^{a-c} \mathrm{e}^{z}{ }_{2} F_{0}\left[1-a, c-a ; \frac{1}{z}\right] .
\end{aligned}
$$

\section{CONCLUSION}

In this paper, we used the differintegral theorems for the confluent hypergeometric equation. We also obtained hypergeometric forms of the fractional solutions. Solutions of the singular equations can be obtained by means of these theorems. 


\section{ACKNOWLEDGMENT}

The author would like to thank the referees for useful and improving comments.

\section{REFERENCES}

[1] Podlubny I. Fractional Differential Equations: An Introduction to Fractional Derivatives, Fractional Differential Equations, Methods of Their Solution and Some of Their Applications, Mathematics in Science and Enginering, USA: Academic Press, 1999.

[2] Miller KS, Ross B. An Introduction to the Fractional Calculus and Fractional Differential Equations, USA: John Wiley \& Sons, 1993.

[3] Oldham KB, Spanier J. The Fractional Calculus: Theory and Applications of Differentiation and Integration to Arbitrary Order, USA: Academic Press, 1974.

[4] Yilmazer R, Ozturk O. Explicit Solutions of Singular Differential Equation by means of Fractional Calculus Operators, Abstract and Applied Analysis, vol. 2013, 2013, 6 pages.

[5] Tu ST, Chyan DK, Srivastava HM. Some Families of Ordinary and Partial Fractional Differintegral Equations, Integral Transform. Spec. Funct. vol. 11, 2001, p.291-302.

[6] Nishimoto K. Kummer's Twenty-Four Functions and N-Fractional Calculus, NonlinearAnalysis, Theory, Methods \& Applications, vol. 30, 1997, p.1271-1282.

[7] Yilmazer R. N-Fractional Calculus Operator $N^{\mu}$ method to a Modified Hydrogen Atom Equation, Math. Commun., vol. 15, 2010, p.489-501.

[8] Whittaker ET, Watson GN. A Course of Modern Analysis: An Introduction to the General Theory of Infinite Processes and of Analytic Functions; With an Account of the Principal Transcendental Functions (Fourth Edition), Cambridge: Cambridge University Press, 1927.

[9] Fukuhara M. Ordinary Differential Equations, Tokyo: Iwanami Shoten, 1941.

[10] Tricomi FG. Funzioni Ipergeometriche Confluenti, Roma: Edizioni Cremonese, 1954.

[11] Watson GN. A Treatise on the Theory of Bessel Functions (Second Edition), Cambridge: Cambridge University Press, 1944.

[12] Yilmazer R, Inc M, Tchie, F, Baleanu D. Particular Solutions of the Confluent Hypergeometric Differential Equation by using the Nabla Fractional Calculus Operator. Entropy, vol. 18 (2), (2016), 6 pages.

[13] Virchenko N. On the Generalized Confluent Hypergeometric Function and Its Application, Fractional Calculus and Applied Analysis, vol. 9 (2), 2006, p.101-108.

[14] Srivastava HM, Saxena RK. Some Volterra-Type Fractional Integro-Differential Equations with a Multivariable Confluent Hypergeometric Function as Their Kernel. Journal of Integral Equations and Applications, vol. 17 (2), 2005, 199-217.

[15] Campos LMBC. On Some Solutions of the Extended Confluent Hypergeometric Differential Equation. Journal of Computational and Applied Mathematics vol. 137, 2001, p.177-200.

[16] Lin SD, Shyu JC, Nishimoto K, Srivastava HM. Explicit Solutions of Some General Families of Ordinary and Partial Differential Equations Associated with the Bessel Equation by means of Fractional Calculus, Journal of Fractional Calculus, vol. 25, 2004, p.33-45. 
[17] Bayın S. Mathematical Methods in Science and Engineering, USA: John Wiley \& Sons, 2006.

[18] Yilmazer R, Bas E. Explicit Solutions of Fractional Schrödinger Equation via Fractional Calculus Operator, Int. J. Open Problems Compt. Math., vol. 5 (2), 2012, p.132-141.

\section{CV / ÖZGEÇMIŞ}

\section{Ökkeş ÖZTÜRK; Yrd.Doç.Dr. (Assist.Prof)}

Lisans derecesini 2009'da Manisa Celal Bayar Üniversitesi Matematik Bölümü'nden, Yüksek Lisans derecesini 2011'de Elazığ Firat Üniversitesi Matematik Bölümü'nden, Doktora derecesini 2015 yılında Elazığ Firat Üniversitesi Matematik Bölümü'nden aldı. Hala Bitlis Eren Üniversitesi Matematik Bölümü'nde öğretim üyesi olarak görev yapmaktadır. Temel çalışma alanları: Kesirli Hesap, Kesirli Hesapta N-Metot, Diferintegral Teoremleri üzerinedir.

He got his bachelors' degree in the Department of Mathematics at Celal Bayar University, Manisa/Turkey in 2009, his master degree in the Department of Mathematics at Firat University, Elazig/Turkey in 2011, PhD degree in the Department of Mathematics at Firat University, Elazig/Turkey in 2015. He is still an academic member of the Department of Mathematics at Bitlis Eren University. His major areas of interests are: Fractional Calculus, N-Method in the Fractional Calculus, Differintegral Theorems. 